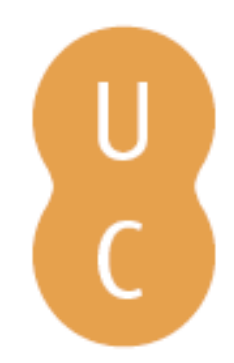

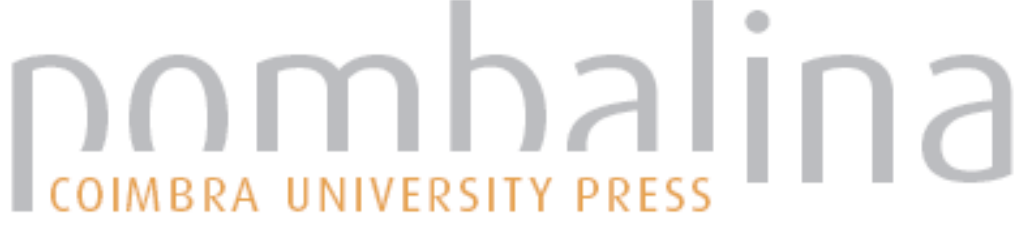

\section{Aspectos de la utopía cómica}

\author{
Autor(es): $\quad$ Melero, Antonio
}

Publicado por: Imprensa da Universidade de Coimbra

URL

persistente: URI:http://hdl.handle.net/10316.2/32051

DOI: $\quad$ DOI:http://dx.doi.org/10.14195/978-989-26-0499-2_7

Accessed : $\quad$ 26-Apr-2023 15:34:24

A navegação consulta e descarregamento dos títulos inseridos nas Bibliotecas Digitais UC Digitalis, UC Pombalina e UC Impactum, pressupõem a aceitação plena e sem reservas dos Termos e Condições de Uso destas Bibliotecas Digitais, disponíveis em https://digitalis.uc.pt/pt-pt/termos.

Conforme exposto nos referidos Termos e Condições de Uso, o descarregamento de títulos de acesso restrito requer uma licença válida de autorização devendo o utilizador aceder ao(s) documento(s) a partir de um endereço de IP da instituição detentora da supramencionada licença.

Ao utilizador é apenas permitido o descarregamento para uso pessoal, pelo que o emprego do(s) título(s) descarregado(s) para outro fim, designadamente comercial, carece de autorização do respetivo autor ou editor da obra.

Na medida em que todas as obras da UC Digitalis se encontram protegidas pelo Código do Direito de Autor e Direitos Conexos e demais legislação aplicável, toda a cópia, parcial ou total, deste documento, nos casos em que é legalmente admitida, deverá conter ou fazer-se acompanhar por este aviso. 
Maria de Fátima Silva

Coordenação

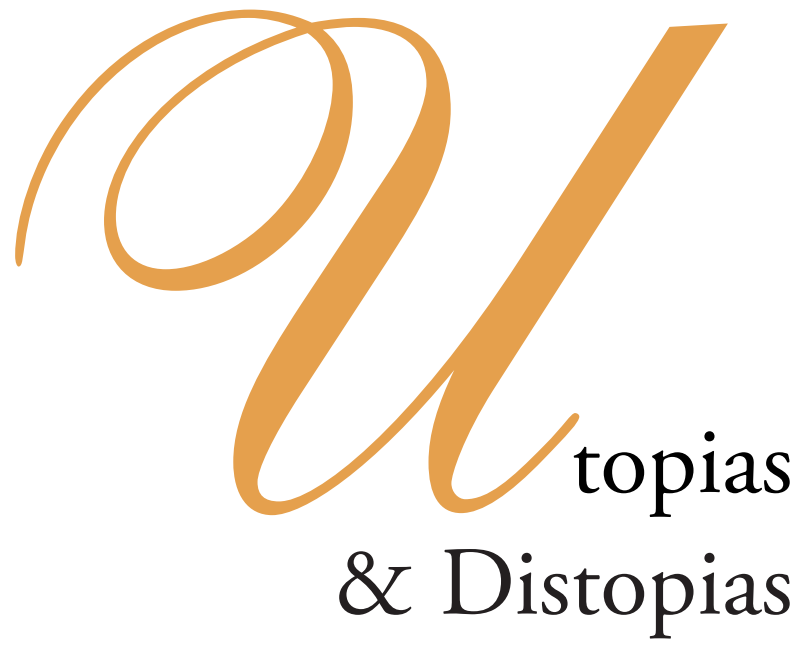




\section{COORDENAÇÃO EDITORIAL \\ Imprensa da Universidade de Coimbra \\ Email: imprensauc@ci.uc.pt \\ URL: http://www.uc.pt/imprensa_uc}

\section{CONCEPÇÃO GRÁFICA}

António Barros

Pré-IMPRESSÃo

Tipografia Lousanense, Lda.

EXECUÇÃO GRÁFICA

Tipografia Lousanense, Lda.

ISBN

978-989-8074-74-4

DEPósito LEGAL

289002/09

OBRA PUBLICADA COM O APOIO DE:

Centro de Estudos Clássicos e Humanísticos

Faculdade de Letras da Universidade de Coimbra

FCT Fundação para a Ciência e a Tecnologia

MINISTÉRIO DA CIÊNCIA, TECNOLOGIA E ENSINO SUPERIOR Portugal 
Maria de Fátima Silva

Coordenação
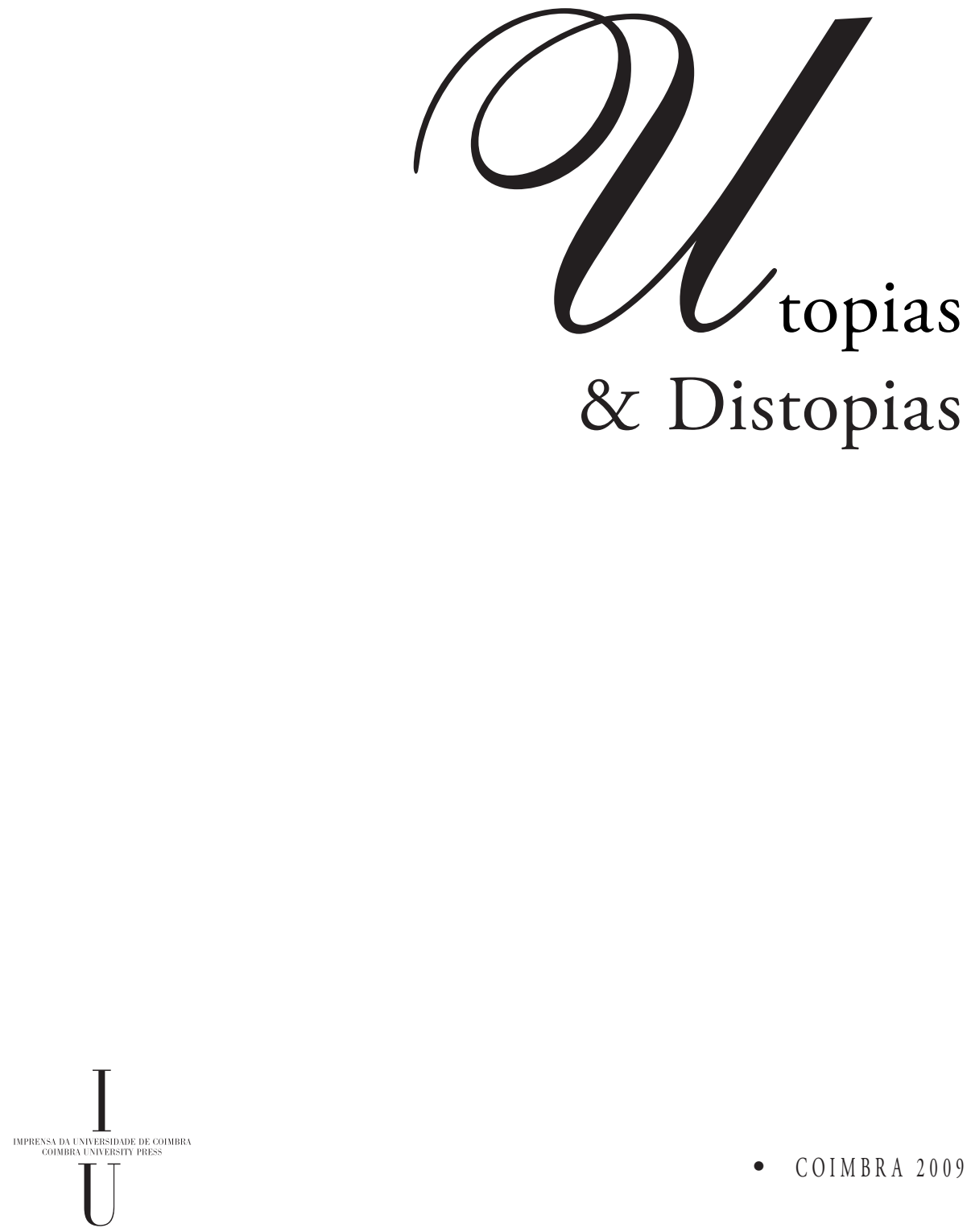

- colmbra 2009 



\section{Antonio Melero}

\section{ASPECTOS DE LA UTOPÍA CÓMICA}

Apenas es necesario insistir en el hecho de que, desde los primeros textos literarios griegos, tenemos bien atestiguada la existencia de unas tradiciones folclóricas, de diferente origen y naturaleza, que, en un sentido muy lato, podemos calificar de utópicas ${ }^{1}$. Y es sabido también que algunas de esas tradiciones folclóricas de carácter utópico están encarnadas en la representación de pueblos que habitan épocas o lugares imprecisos, pero que, en algunos casos podemos sencillamente definir como "otro mundo"2.

A grandes rasgos $\mathrm{y}$, sin adentrarnos en análisis más detallados, podemos hablar de dos grandes tradiciones folclóricas que nos hablan de pueblos felices: una que contiene el recuerdo de una edad de oro, situada en un pasado remoto o en un espacio lejano e indefinido; y aquella otra que presenta la idílica situación de un mundo automático, donde todo lo necesario para la existencia se produce espontáneamente, el topos del aưtónatos ßíos, de tan larga tradición literaria. Me apresuro a ańadir que esas tradiciones no son totalmente independientes, sino que con mucha frecuencia comparten temas y rasgos comunes, como el de un mundo en paz, una existencia humana libre de trabajos, dolores y preocupaciones y una vida larga consumada en una muerte indolora, si bien difieren también en sus formas y propósitos literarios ${ }^{3}$.

\footnotetext{
${ }^{1}$ Existe una amplia bibliografía sobre la cuestión, desde obras que discuten, como es el caso de MOSES FINLEY (Uso y Abuso de la Historia, trad. esp. Barcelona, 1984, pp. 273-949), la existencia de auténticas utopías en la antigüedad, a otras que se limitan a una clasificación temática de las distintas tradiciones o defienden abiertamente la idea de utopía en pie de igualdad con la literatura occidental que inauguró la obra de Moro. Entre la extensa bibliografía recogemos HORST BRAUNERT, Utopia. Antworten griechischen Denkens auf die Herausforderung durch soziale Verhältnisse, Kiel, 1969; RUDOLF VILLGRADTER \& FRIEDICH KREY, Der utopische Roman, Darmstadt, 1973; HELMUT FLASHAR, Formen utopischen Denkens bei den Griechen, Innsbruck, 1974; JOHN FERGUSON, Utopias of the Classical World, Londres, 1975; LAWRENCE GIANGRANDE, "Les utopies grecques" Rev. Et. Anc. LXXVIII-LXXIX, 1976-77, pp. 120-128; LUCIO BERTELLI, "L'Utopia greca" en L. FIRPO ed. Storie delle idee politiche, economiche e sociali, Vol. I, Turín, 1982, pp. 463-581; MARISA GHIDINI TORTORELLI, Miti e utopia nella Grecia antica, Annali Ist. It. St., V. 1976/1978; Doyne Dawson, Cities of the Gods.Communist Utopias in Greek Thought, N.Y-Oxford, 1992, a la que cabe añadir la útil antología de J. LENS TUERO \& J. CAMPOS DAROCA, Utopias del mundo antiguo, Madrid, 2000.

${ }^{2}$ Para una visón de conjunto vid. RAYMOND TROUSSON, Historia de la Literatura Utópica, trad. esp. Madrid, 1995, pp. 55 ss.

${ }^{3}$ Para los temas vid. J.LENS, Utopias del mundo antiguo, pp. 43-54.
} 
Mi interés se centra en investigar los procedimientos lingüísticos y narrativos con los qué se construye la utopía. Averiguar las operaciones lingüísticas por las que algo ignoto, desconocido, fantástico e inexistente es traducido al lenguaje familiar. Cómo se crea lingüísticamente una realidad nueva e inexistente mediante lo viejo, conocido y cotidiano.

A pesar de la bibliografía relativamente abundante sobre las tradiciones utópicas griegas, pocas son las que se han ocupado de los procedimientos narrativos de las mismas ${ }^{4}$ entre otras razones, porque, al primar el contenido sobre la forma, bajo la rúbrica única de "Utopía" caben tanto relatos como la Edad de Oro hesiódica, la Esqueria de la Odisea, fábulas cómicas como Las Asambleístas de Aristófanes, propuestas utópicas como La República de Platón o novelas fantásticas como las de época helenística.

Pues bien, para ir adentrándonos en nuestro tema de las utopías folclóricas, digamos ya desde el comienzo que en las tradiciones utópicas folclóricas o populares 5 no hay elementos de teorización estatal o política ${ }^{6}$. Son un relato fantástico y, como tal, su eficacia se logra por procedimientos expresivos que apelan no a la razón, como en el caso de los utopistas griegos, sino a la imaginación y el sentimiento. Y por ello los procedimientos lingüísticos se orientan a conseguir esos efectos. Dichos relatos muestran más afinidad con los cuentos populares en algunos elementos narrativos, o con la magia, en la medida que su eficacia no depende de su veracidad o eficacia, sino de la adhesión sentimental del oyente.

Apelar afectivamente a los sentimientos de los oyentes precisa de procedimientos lingüísticos o narrativos que provoquen una respuesta emotiva. No voy a insistir ahora en el recurso a palabras claves, cuya eficacia aparece ya desde los primeros textos. De ese procedimiento me he ocupado in extenso en otro lugar ${ }^{7}$. Básteme recordar que ya

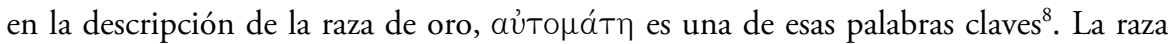
de oro del mito hesiódico es también semejante a los dioses. Ello se expresa con una

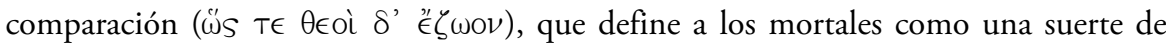
dioses felices - en eterna juventud y perpetuo festín- de los que se distinguen exclusivamente por el hecho de morir, si bien la muerte se ve reducida a una suerte de sueño. El tercer elemento utópico es el de una paz idílica, definida como una

\footnotetext{
${ }^{4}$ FELIX JACOBY en su artículo sobre Hecateo en la R.E. hace, de pasada, una interesante observación sobre la eficacia de la técnicas narrativas de las utopías etnográficas: "die Einkleidung wurde vielfach mit soviel Liebe und Kunst ausgearbeitet, dass sie den vollen Schein der Wahrheit erhielt”.

${ }^{5}$ Vide NORTHROP FRYE, "Varieties of Literary Utopias", Daedalus 94 (1965), pp. 323-47. Para un examen de las tradiciones utópicas griegas, algunos de sus temas y las funciones del relato utópico, vide, además de la bibliografía ya citada, MARIANO NAVA, "Politeia y Utopía. Elementos para una poética de la utopía filosófica en Grecia" en LABIANO ILUNDAIN, J.M., LÓPEZ EIRE, A. Y SEOANE PARDO, A. (eds.), Retórica, politica e ideología desde la Antigüedad hasta nuestros días. Actas del II Congreso Internacional "Retórica, politica e ideología desde la Antigüedad hasta nuestros días", Salamanca 1997, pp. 229-34.

${ }^{6}$ Para estas distinciones así como para la discusión sobre si existió en la Antigüedad un verdadero pensamiento utópico vid. M. FINLEY, Uso y Abuso de la Historia, passim.

7 "La Lengua de la Utopía", en A. LÓPEZ EIRE\&AGUSTÍN RAMOS GUERREIRA, Registros Lingüisticos en las lenguas clásicas, Salamanca, 2004, pp. 149-172.

${ }^{8}$ Op. cit. 109-119.
} 
jंouxía, una paz o tranquilidad voluntaria9. Los hombres de la Edad de oro eran divinos, en un mundo automático, de abundancia y de paz.

Constatamos que el texto de Hesíodo es meramente descriptivo. No hay en él ninguna propuesta teórica y su eficacia resulta de su contraposición con la raza de hierro que al poeta y a sus contemporáneos le ha tocado vivir. La raza de oro no es más que el

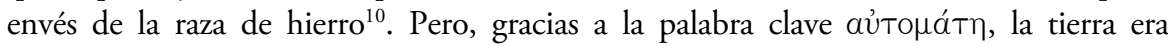
presentada como una especie de autómata al servicio de la humanidad. No basta pues para construir la utopía la acumulación de elementos de contenido - paz, abundancia, festines, juventud eterna, etc. - hay que suscitar también la representación plástica y la reacción emotiva del auditorio mediante el empleo de esas mágicas palabras claves.

Si el texto de Hesíodo es fundamental para la historia de la utopía popular en el primer arcaísmo griego, no es ciertamente el único. Vestigios de automatismo los hallamos también en numerosos pasajes de Homero ${ }^{11}$. Pero, por otro lado, ya en Homero encontramos indicios de tradiciones utópicas distintamente formuladas sobre las que no se ha llamado debidamente la atención. En un brevísimo pasaje (Ilíada, XIII, 3-7), Zeus, harto del fragor de la guerra, aparta su mirada del combate, donde deja a Héctor y a los troyanos junto a las naves de aqueas:

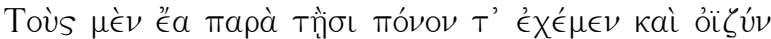

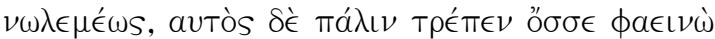

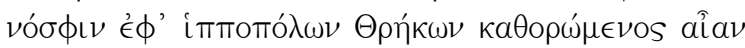

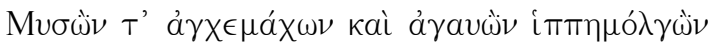

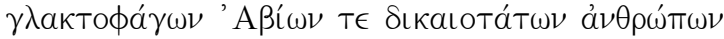

"Los dejó junto a ellas (las naves) soportando fatigas y miserias

Sin cesar; y él desvió a los lejos sus ojos brillantes

Para contemplar la tierra de los tracios, criadores de potros,

Y de los misios que luchan de cerca y la de los nobles hipemolgos

Que se alimentan de leche y la de los Abios,

los más justos de todos los hombres".

Es evidente que estos pueblos lejanos representan un espectáculo caro a Zeus. Pero notemos que entre los más o menos nebulosos Tracios, Misios e Hipemolgos - donde, tras una vaga noticia etnográfica, se deja ver el gusto por lo exótico -, se encuentran los

\footnotetext{
${ }^{9}$ Aunque lleva razón J. LENS ("La representación de la Edad de Oro desde Hesíodo hasta Pedro Mártir de Anglería" en Pervivencia y actualidad de la cultura clásica, GARCÍA GONZÁLEZ J. MA. \& POCIÑA PÉREZ A. (eds.) Universidad de Granada, 1996, pp. 173-209) al considerar que la iंбuxía hesiódica se sitúa en los inicios de toda la tradición irenística posterior, conviene no perder de vista, sin embargo, que el relato hesiódico pertenece a un momento prepolítico, anterior a la raza de hierro, y que su opuesto, como se desprende del texto siguiente es ßía, que en Hesíodo implica injusticia. Interesantes son también las distinciones que el trabajo propone entre las diferentes tradiciones utópicas griegas.

${ }^{10}$ Para una análisis del mito de las razas vid. JEAN-PIERRE VERNANT, Mito y pensamiento en la Grecia antigua, trad. esp. Barcelona, 1993, pp. 21-88.

${ }^{11}$ Il. V 749 cuando Atenea desciende del Olimpo para socorrer a los Aqueos las puertas del cielo se abren aujtovmatai; XVIII 376 Hefesto fabrica unos trípodes que se desplazan automáticamente y dispone para su servicio de unas áureas doncellas autómatas (418); Od. VII 91-95 se mencionan los prodigiosos perros de oro y de plata, fabricados por Hefesto, que guardaban las puertas del palacio de Alcínoo.
} 
"A $\beta \iota \mathrm{o}$, un pueblo evidentemente utópico, situado en un lugar indeterminado, lejano en todo caso, a donde sólo llega la penetrante mirada de Zeus. La tradición utópica opera en este caso con procedimientos lingüísticos y narrativos distintos a los de Hesíodo. Es notorio el uso de un étnico parlante, que encarna con su solo nombre uno de los anhelos que hemos encontrado ya en el texto de Hesíodo: el deseo de paz, manifiesto en la renuncia a la violencia, a ßía. Este rasgo los convierte en los más justos de todos los hombres. El brevísimo pasaje codifica lingüísticamente un elemento fundamental de la utopía - la paz y la justicia que de ella se deriva- de forma muy eficaz, echando mano además de un procedimiento del que se servirán muchas utopías posteriores. Observemos que un pueblo a todas luces inexistentes como los Abios es situado en una serie de pueblos existentes, como los tracios, los misios y los hipemolgos, de los que se dan ciertas informaciones etnográficas: son ordeñadores de yeguas y bebedores de leche. Al insertar a los Abios en una serie de pueblos más o menos definidos, se vuelven verosímiles y la utopía se encuentra, en cierto modo, confirmada por su propia formulación.

Los Abios son caracterizados por un rasgo moral. Son pacíficos y su renuncia a la violencia tiene como consecuencia dotarlos de una superioridad moral inusitada: una justicia perfecta, topos que, como veremos, encontraremos en muchos otros relatos del género. "Los más justos de los humanos", un superlativo, que refuerza la fuerte emotividad del nombre parlante, que es, a su vez, la palabra clave. Incluso en un

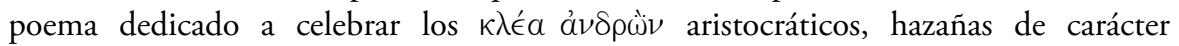
fundamentalmente guerreras, no falta la utópica representación de un mundo sin violencia. La tendencia moralizante de la literatura griega se hace presente ya desde los primeros momentos.

Observemos que la asociación de la ausencia de violencia con la justicia estuvo presente en todo el pensamiento arcaico, donde encuentra formulaciones muy explícitas. Así Hesíodo aconseja a su hermano (Op. cit. 274-75) ${ }^{12}$ :

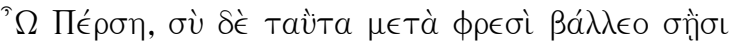

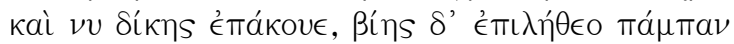
"Perses, métete esas reflexiones en tu corazón
$Y$, en consecuencia, atiende la voz de la Justicia
y olvídate por completo de la violencia”.

El breve pasaje homérico está, pues, en los orígenes griegos de la utopía etnográfica, llamada a tener un éxito enorme en la literatura Griega. En él encontramos ya in nuce los elementos que van a definir la literatura utópica griega de inspiración folclórica: nombres parlantes, superlativos, palabras claves, detalles pormenorizados de una realidad inexistente, presentada, sin embargo, mediante sofisticados procedimientos narrativos, como verosímil.

La fuerte emotividad original del pasaje, sugerida por el nombre clave y parlante de

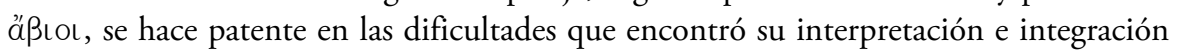

\footnotetext{
${ }^{12}$ Cf. op. cit. 321-326, donde la riqueza obtenida por la fuerza encuentra el castigo de los dioses.
} 
en la literatura griega posterior ${ }^{13}$. Muy pronto se trató de explicar su significado - no olvidemos que, morfológicamente åßıos puede ser tanto un derivado de ßía, ßíos y ßıós - y de incluirlo dentro de alguna de las series geográficas/etnográficas que se elaboraban para llenar las tierras desconocidas o mal conocidas. La autoridad de Homero, por un lado, y el deseo de conocimientos etnográficos, por otro, de pueblos habitantes de los extremos de la tierra, hicieron que un compuesto tan transparente como åßıos, correctamente interpretado por algunos autores ${ }^{14}$, fuera objeto de todo tipo de especulaciones.

La primera reelaboración conservada de este pueblo utópico la encontramos en Esquilo, en un fragmento del Prometeo Liberado (fg. 196 Radt), donde volvemos a encontrar una nueva mención de los útópicos Abios homéricos. Prometeo predice a Heracles sus futuros errabundeos. En el curso de ellos, Prometeo anuncia a Heracles:

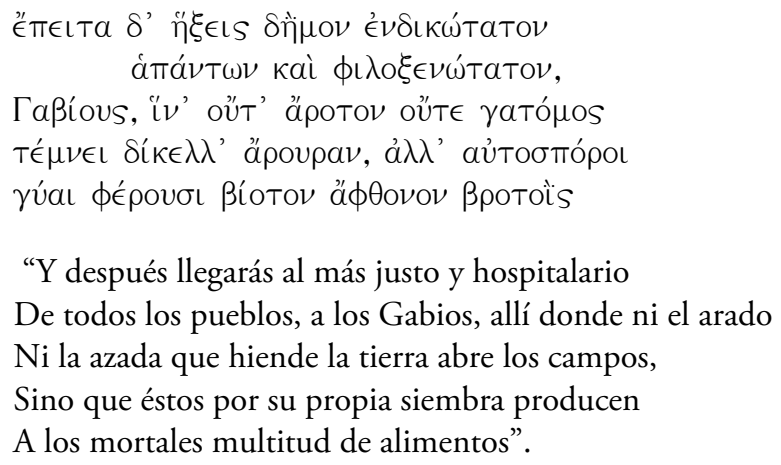

El fragmento de Esquilo inscribe a los Gabios en una serie de pueblos, de los que sobresalen por constituir un pueblo fantástico. El texto claramente utópico contamina las dos tradiciones a las que nos referimos al comienzo: una tierra automática, que se siembra a sí misma (aủToбTópol) y generosa y un pueblo absolutamente justo y

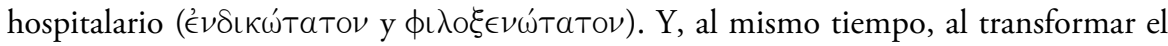
nombre del pueblo, le proporciona una nueva etimología a los misteriosos äßıo homéricos. Ahora son ya no sólo pacíficos y hospitalarios, sino alimentados por la tierra misma. Todo hace pensar que Esquilo en este pasaje deriva a los Abios de ßíos, haciendo de ellos uno de esos múltiples pueblos felices situados en los límites de la

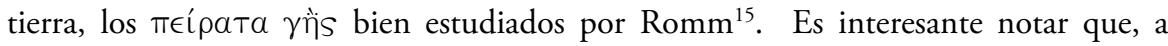
pesar de la posible nueva etimología, Esquilo mantiene el adjetivo homérico

${ }^{13}$ Ilustrativa de las diversas interpretaciones del étnico es la noticia de Estobeo (Florilegio 149. 64.7):

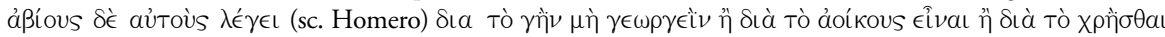

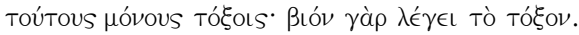

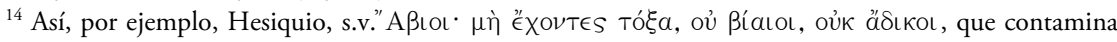

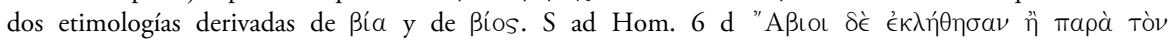

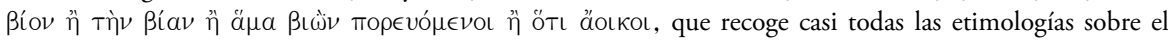
étnico.

${ }^{15}$ JAMES S. ROMM, The Edges of the Earth in Ancient Thought: Geography, Exploration, and Fiction, Princeton, 1992. 


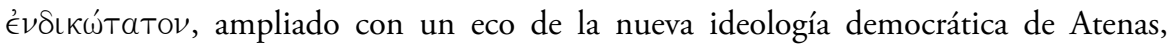
$\phi \iota \lambda о \xi \in \nu \omega ́ \operatorname{Tato\nu .~}$

El pasaje de Esquilo muestra de modo claro un rasgo característico de la cultura griega, debido, muy probablemente, al hecho de que durante mucho tiempo fuera oral: la tendencia a no desechar ninguna información recibida, aunque ésta esté en abierta oposición a los datos de la experiencia. Es ésta tendencia la que tanto complicó el desarrollo de una geografía libre de excrecencias míticas. Podemos hablar de una "manía conservacionista" de modo semejante a como se ha hablado de una manía cíclica, nacidas ambas del deseo de ordenar la tradición en conjuntos coherentes. Pero la tendencia implicaba paralelamente la necesidad de adaptar la tradición a la sensibilidad del momento, adecuarla a eso que se ha dado en llamar el imaginario colectivo.

No deben de extrañarnos, pues, las dificultades que produjeron los Abios homéricos a los autores posteriores, que hicieron todo tipo de especulaciones para eliminarlo del texto homérico, situarlos geográficamente o dartes una explicación etnográfica y etimológica más satisfactoria. Y la razón de tales dificultades es que para los griegos, en razón de la mencionada tendencia, los Abios eran tan reales como los otros pueblos junto a los que aparece. Y si ello era así, surgía inevitablemente la necesidad de integrarlos en el mundo.

Durante todo la Antigüedad el breve pasaje de Homero no dejó de ser continuamente reinterpretado geográfica y etnográficamente, porque ya no se entendía el simple y efectivo procedimiento lingüístico de construcción de la utopía ${ }^{16}$. Perdida la perspectiva utópica se adoptó un punto de vista etnográfico y/o lingüístico. De esa etnografía griega que se mueve entre lo real y lo fabuloso y que debemos de leer casi como un género literario.

\footnotetext{
${ }^{16}$ Citaré sólo por vía de ejemplo algunos de los intentos de integración o explicación y las maniobras lingüísticas implicadas. Elio Herodiano los considera escitas e intenta dar una explicación del nombre apoyándose en autoridades conocidas: siguiendo a Alejandro, quien a su vez se apoya en Diofanto, deriva su nombre del río Abiano. Añade, sin embargo, valiéndose de la autoridad de Dídimo, Filostéfano y otras fuentes, que su nombre se debe a que no llevan una vida sedentaria ( $\beta$ íos) y viajan continuamente sobre carretas. Pero es que ni el propio Estrabón pudo tampoco escapar en este caso del peso de la tradición homérica. Tras considerarlos nómadas, siguiendo a Heráclito, pasa a enumerar algunas costumbres de estos nebulosos pueblos: escitas, sármatas, tracios y taúricos. En su relación de estas confusas tribus Estrabón retiene algunos rasgos utópicos o, si se quiere, de "buen salvaje". Así, siguiendo a Posidonio

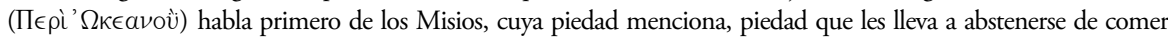
nada animado, alimentándose sólo de leche, queso y miel y llevando una vida pacífica

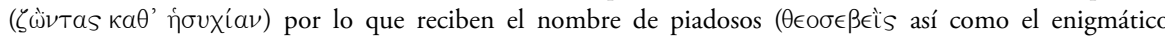

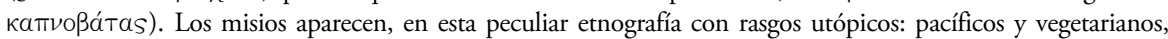
como otros tantos pueblos semejantes. Y a propósito de los Abios, que llevan un género de vida semejante, además de identificarlos con los hipemolgos, nos explica que derivan su nombre del hecho de vivir sin esposas:

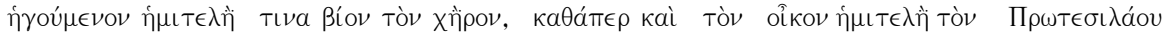

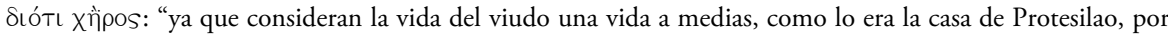
ser viudo". Ningún reparo, como vemos, a utilizar el mito como fuente de una etimología etnográfica. Estobeo que reúne en su Florilegio casi todas las especulaciones etnográficas sobre los Abios añade otra muy común que deriva su nombre de ßıós (arco). Y Harpocración nos informa de que Antifonte usó el adjetivo

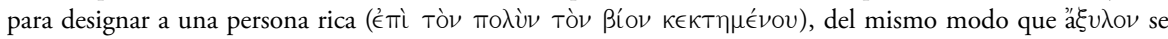
podía predicar de un bosque frondoso (con mucha $\xi u ́ \lambda o \nu$ ). Aquí se dejan traslucir las especulaciones sofísticas sobre el lenguaje y su crítica de las informaciones etnográficas tradicionales.
} 
Y otro tanto podría decirse, con matices, de los Feacios. Un examen detallado de los Feacios nos muestra también los procedimientos lingüísticos y narrativos para la construcción de una utopía ${ }^{17}$. A pesar de los muchos rasgos que caracterizan a los feacios como un pueblo relativamente moderno en el panorama de la civilización homérica, un pueblo que guarda memoria de sus migraciones y del proceso de colonización, otros muchos elementos los caracterizan como un pueblo de "otro mundo", característica que deroga la validez y exactitud de los datos geográficos que orientan la llegada de Ulises a su país. Nombre parlante, pacifismo aislacionista, autómatos bios, autómatas mecánicos y naves automáticas denuncian el origen folclórico de una tradición contaminada, sin duda, por otros rasgos de la ideología colonial. El relato de los Feacios inaugura una tradición llamada a tener un gran éxito literario: el de la isla fabulosa, situada en los márgenes del mundo, que frecuentemente es el Océano, el límite extremo que permite definir el centro, como bien ha explicado Pietro Janni ${ }^{18}$. Al Océano, es decir a los límites del mundo estaban asociadas representaciones de pueblos y de países extraordinarios.

Tradiciones folclóricas semejantes e integraciones geográfico-etnográficas parecidas encontramos en Homero y en la literatura posterior a propósito de otros pueblos como los Etíopes, descritos con procedimientos narrativos que los hacen pueblos claramente utópicos: viven en los dos extremos del mundo, a las orillas del Océano, su belleza física es excepcional ${ }^{19}$, son piadosos y ofrecen hecatombes a los dioses. Y están asentados en el lejano Sur, como una réplica de sus míticos antípodas, los Hiperbóreos del Norte ${ }^{20}$. Su inclusión en una serie de pueblos reales bien conocidos - chipriotas, fenicios, egipcios, sidonios y erembos - que no pueden ser definidos como pastores repite el procedimiento narrativo de incluir lo inverosímil en lo real o lo verosímil. Y no menos utópica es la descripción de una abundancia donde la naturaleza voluntariamente contraviene sus propias leyes. Y etnografía utópica subyace a las noticias de Heródoto sobre los etíopes ${ }^{21}$ cuyos ecos llegan hasta las Etiópicas de Heliodoro $^{22}$ : su enorme riqueza y su desprecio del oro que les hace burlarse de los

${ }^{17}$ El propio nombre de los Feacios parece ser un nombre parlante, si hemos de creer las etimologías más autorizadas; vid. P. CHANTRAINE, Dictionnaire étymologique de la langue grecque, s.v. фalós. La denominación de "Los grises" sugiere un pueblo del más allá, situado en un mundo distinto al de los humanos. Y, si alguna duda nos cupiera de ello, el propio Homero nos confirma esta ubicación ultraterrena.

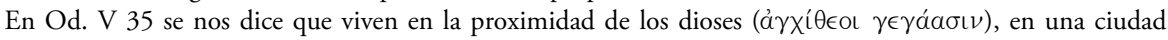
fundada cuando huyeron de la proximidad de los Cíclopes, criaturas violentas. Cf. VI 1 ss.. En la nueva ciudad fundada por Nausítoo, en los confines del mundo, y regida por Alcínoo, los Feacios llevan una vida feliz, libres de guerras y violencias (VI 199-205), el mismo motivo que habíamos ya encontrado a propósito de los Ábios, en el contexto de un relato de fundación. En los extremos del mundo, en la proximidad de los dioses, libres de guerras, dedicados a las artes del mar, que expresamente se oponen a la guerra (VI 262-282), disfrutando de una cosecha perpetua, como los hombres de la Edad de Oro hesiódica, VII 114 ss. y con naves automáticas VIII 555-574.

${ }^{18}$ PIETRO JANNI, “Los límites del mundo entre el mito y la realidad: evolución de una imagen” en Los limites de la tierra: el espacio geográfico en las culturas mediterráneas, AURELIO PÉREZ JIMÉNEZ\&GONZALO CRUZ ANDREOTTI eds., Madrid, 1998, pp. 23-40.

${ }^{19}$ Il. I 423; Od., I 22; XI 522, donde la belleza de Memnón es presentada como paradigmática.

${ }^{20}$ Para esta exacta correspondencia de pueblos boreales y australes vid. h..Hom. Dion. VII 28; Pi. I. VI 23.

${ }^{21}$ III 23.

${ }^{22}$ IX 2. 
embajadores de Cambises, ataviados muy a la manera asiática, con sus mejores galas. O las noticias, también a propósito de Etiopía, de la Mesa del Sol (III 18), en la que los magistrados depositaban durante la noche alimentos que eran recogidos y consumidos durante el día por los pobres. El país del $\mathrm{Sol}^{23}$, por intermedio de esta vieja tradición de la Mesa del Sol ${ }^{24}$, aparece ya aludido en Heródoto. ${ }^{25}$

Aún podríamos citar algunos otros ejemplos de pueblos felices en Homero, como Siria, la patria original de Eumeo, situada también en los extremos del mundo

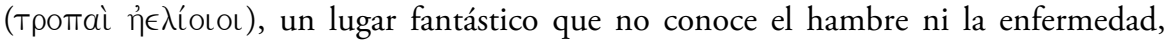
tierra extraordinariamente fértil en ganado y cosechas, donde se experimenta de una abundancia sin límite y se experimenta de una muerte feliz, proporcionada por Apolo y Ártemis ${ }^{26}$.

Por estos y otros indicios existe la fundada sospecha de que Heródoto bebió de una tradición de etnografía utópica, que desgraciadamente conocemos mal, pero de la que intuimos su interés por los pueblos remotos y su tendencia a mejorar el orden social, presentándose como una alternativa crítica al presente ${ }^{27}$. Numerosas noticias de Heródoto nos hacen pensar en la existencia, hoy perdida, de una tradición de etnografía utópica: de ella depende en sus noticias sobre los ya mencionados hipemolgos, los Arimaspos ${ }^{28}$, los Argipeos ${ }^{29}$ - un pueblo pacífico, vegetariano y que desconoce las armas de guerra -, los Agatirsos ${ }^{30}$ con su comunidad de mujeres, los Hiperbóreos $^{31}$, o las fuentes de las que depende para componer la historia de Anacarsis ${ }^{32}$.

En un excelente estudio ${ }^{33}$ John Ferguson ha establecido la tópica de unas tradiciones que él denomina algo anacrónicamente "el buen salvaje", pero que contiene los elementos imaginarios de pueblos felices: junto a la abundancia y generosidad de la tierra de que gozan los ya mencionados feacios o etíopes o los venturosos habitantes de las Islas de los bienaventurados; o el paraíso de los hiperbóreos o de los Gabios, otros rasgos señalan la excepcionalidad de estos e[scatoi. En algunos casos su felicidad parece ir unida a una dieta especial, sea carne, como los etíopes, leche, como los hipemolgos o una simple dieta vegetariana. En muchos casos, son excepcionalmente longevos y de una talla y belleza extraodinaria. Desde el punto de vista moral son particularmente justos y, en ocasiones, presentan una estructura social particular, donde bienes y familias son comunitarios, y donde el sexo no representa

\footnotetext{
${ }^{23}$ El país del Sol aludido ya en Mimnermo fg. 11 West; Eurípides fg. 771 Nauck. Yambulo parte de Etiopía para sus viajes a las islas del Sol.

${ }^{24}$ Para un comentario vide L. GERNET, Antropología de la Grecia clásica, pp. 133 s.

${ }^{25}$ Hdt. III, 18.

${ }^{26} \mathrm{Od}$. XV 403-411.

${ }^{27}$ Vide MOSES HADAS, "Utopian Sources in Herodotus", Class. Philol., 30, 2 (1935) pp. 113-121.

${ }^{28} \mathrm{Hdt}$. III 116 y IV 27.

${ }^{29}$ Hdt. IV 23.

${ }^{30}$ Hdt. IV 104.

${ }^{31}$ Hdt. IV 32. Cf.B. III 23-62 M. ALBADALEJO VIVERO, "Los hiperbóreos, "benefactores" de Grecia” Polis 1998 pp. 5-28.

${ }^{32}$ Hdt. IV 76-77. En época romana se utilizaron unas apócrifas Cartas de Anacarsis para defender la superioridad del noble salvaje sobre los artificios de la civilización. Vid. Cicerón Tusc. disp. V 90; Frontón I 136.

${ }^{33}$ Utopias of the Classical World, Londres 1975, pp. 18-21.
} 
ningún elemento de legitimidad y, en consecuencia, de rivalidad. Reconocemos en estas formulaciones los rasgos elementales de la fantasía folclórica utópica: o bien abundancia que suprima la rivalidad y la envidia o una austeridad casi cínica avant la lettre, donde esos sentimientos no encuentran asiento.

Es, por otro lado, de sobras conocido que la representación arcaica del mundo lo imaginaba como un disco de tierra sólida, rodeada por un gran río llamado Océano del que nacían y fluían grandes ríos como el Nilo, el Fasis, el Istro y el Eridano, que contribuían a conformar una imagen geométrica y en muchos aspectos simétricos de la tierra. Esta representación persistió durante mucho tiempo, si bien hubo de ir ampliándose, a medida que el mundo geográfico conocido se ampliaba ${ }^{34}$. Y en la evolución de esa imagen los márgenes de la tierra se fueron poblando de pueblos exóticos, en muchos aspectos utópicos en la medida en que habitaban fuera del mundo, en otro mundo ${ }^{35}$.

El carácter utópico de esas tradiciones se hace patente en el recuso que a ellas hizo la comedia griega antigua ${ }^{36}$. Las diversas tradiciones de pueblos felices y exóticos reaparecen como un contrapunto utópico y feliz, carnavalesco ${ }^{37}$, a las miserias del presente $^{38}$. También como un procedimiento de inversión y subversión temporal de la realidad. En un breve pasaje del libro VI de sus Deipnosopistae, Ateneo nos da algunos pasajes de comedias que trataban $\pi \in \rho \grave{~}$ toù ápxaíov ßỉov, siete dramas en concreto: los Plutos de Cratino, las Bestias de Crates, los Anfictiones de Teleclides, los Mineros y Persas de Ferécrates, los Turiopersas de de Metágenes y las Sirenas de Nicofonte, a las que añade, sin citar texto alguno, los Freidores de Aristófanes ${ }^{39}$.

Diversamente modulada, la utopía cómica aparece como edad de Crono, con un fuerte componente político y gastronómico en los Plutos de Cratino. Las dificultades de reconstrucción que el fragmento mayor (fg.171) plantea son numerosas, si bien hay un cierto consenso en que la comedia presentaba un coro de Plutoi, que como

\footnotetext{
${ }^{34}$ Vide PIETRO JANNI, “Los límites del mundo entre el mito y la realidad: evolución de una imagen” en Los Límites de la tierra: el espacio geográfico en las culturas mediterráneas, AURELIO PÉREZ JIMÉNEZ\&GONZALO CRUZ ANDREOTTI eds., Madrid, 1998, pp. 23-40. Para la sucesiva adaptación de las tradiciones etnográficas a una imagen del mundo cada vez más amplia, vide ALAIN BALLABRIGA, Le Soleil et le Tartare. L'image mytique du monde en Grece archaique, Paris, 1986.

${ }^{35}$ Vide L. GERNET, Antropología de la Grecia clásica, pp. 123-35.

${ }^{36}$ Muy bien estudiadas por Marcella Farioli, Mundus Alter. Utopie e distopie nella commedia greca antica, especialmente pp. 3-26. Vid.también Ian Ruffell, "The World turned upside down: Utopia and Utopianism in the fragments of Old Comedy" en The Rivals of Aristophanes. Studies in Athenian Old Comedy, David Harvey\&Joh Wilkins eds. Londres 2000, pp. 473-506 y P. Cecarelli, Le monde sauvage et la cité dans la comédie ancienne ibidem, pp. 453-71.

${ }^{37}$ Vide para el análisis bachtiniano de la utopía cómica J. C. Carrière, Le Carnaval et la politique.Une introduction a la comédie gecque, París, 1979.

${ }^{38}$ Aunque la comedia supo hacer burla política de la representación utópica del autómatas bios, como bien muestra P. Cecarelli, "L'Athènes de Périclès: un pays de cocagne? L'idéologie démocratique et l'autómatos bios dans la comédie ancienne, QUCC n.s. 54 (1996), pp. 109-59.

39 Lo que interesaba a Ateneo eran los motivos gastronómicos. Para ellos remitimos al estudio fundamental de Matteo Pellegrino, Utopie e Immagini gastronomiche nei frammenti dell 'archaia, Bolonia, 2000, Eikasmos, Studi 4, quien añade al elenco de Ateneo otros fragmentos como el fg. 333 K\&A de las Segundas Tesmoforiantes, pp. 156 ss.; de las Estaciones de Aristófanes (fg. 581 K\&A) pp. 173 ss., de los

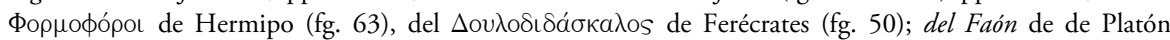
cómico (fg. 189).
} 
Titanes de la Edad de Oro, regresan a Atenas, con la que les une alguna afinidad, para restablecer una mayor justicia, especialmente un más justo reparto de la riqueza ${ }^{40}$. La obra contenía un ataque a Hagnón y quizás a otros nuevos ricos del entorno de Pericles, que quizás, como en otras obras de Cratino, era el verdadero objeto del ataque. Pero, a pesar de las dificutades del pasaje, algunos rasgos de la gramática utópica se dejan percibir: la mezcla de lo maravilloso con lo real, como en esa presentación formal pero con claras resonancias épicas de los Plutoi (v. 11 TıTàveS

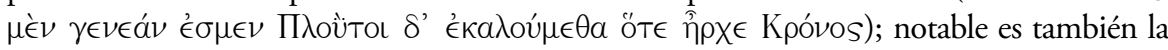
acumulación de alimentos (vv. 49 ss.); la fusión sorprendente del plano mítico con la realidad ateniense más directa (vv. 66 ss. con fórmulas legales y mención de personajes históricos como Hagnón). Procedimientos todos ellos de la utopía cómica, que reaparecen en otros fragmentos de la obra. Pero, además de dichos procedimientos, es interesante observar las variantes que algunos temas tradicionales presentan. El fg. 172,

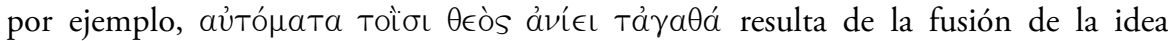

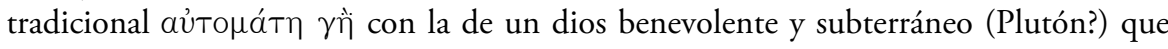
envía bienes a los mortales. En fin, el fg. 176,

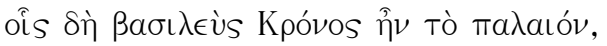

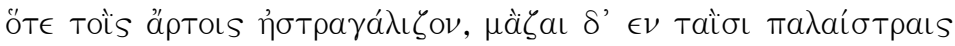

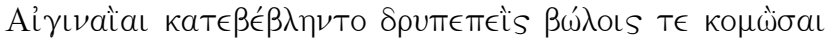

\section{"Su rey era antiguamente Crono,}

Cuando jugaban a los dados con panes de trigo y en las palestras

Colgaban tortas de Egina, tiernas y llenas de grumos como terrones".

evoca la representación de un universo fantástico, hecho verosímil mediante imágenes sorprendentes, donde la excepcional abundancia gastronómica comparte el espacio cotidiano del juego o del ejercicio físico.

Los Anfictiones de Teleclides ${ }^{41}$ (fg. 1), dependen directamente del pasaje hesiódico estudiado. Un personaje, quizás el propio Crono, hace una descripción de las condiciones de vida en la Edad de Crono ${ }^{42}$ :

"Voy a decir la forma de vida que, al comienzo, yo ofrecía a los mortales. En primer lugar, había paz para todos: corría como el agua entre los dedos. La tierra no producía miedo ni enfermedades, sino que todo lo necesario se ofrecía espontáneamente: así el vino corría por las torrenteras, los panes de centeno se disputaban con los de trigo el paladar de los hombres, suplicándoles que se tragaran de un solo bocado a los más blancos, si obtenían de ello alguna satisfacción. Los peces marchaban a las casas, se asaban a la perfección ellos mismos para ir a servirse sobre las mesas. Un río de caldo, con remolinos de trozos de carne humeante, corría junto a los lechos; cańos de salsa picante estaban al alcance de quien quisiera gustarlo, de modo que había abundancia

\footnotetext{
${ }^{40}$ Una discusión sobre labra y las tentativas de reconstrucción en M. Farioli, Mundus Alter, pp. 31 ss. Un comentario minucioso en M.Pellegrino, Utopie e immagini gastronomiche, pp. 45 ss.

${ }^{41}$ Fg. 1 K\&A.

${ }^{42}$ Un excelente comentario a este y otros fragmentos de temática semejante de la comedia antigua puede leerse ahora en Matteo Pellegrino, Utopie e Immagini gastronomiche nei frammenti dell' Archaia, Eikasmos (Studi 4), Bolonia, 2000.
} 
para que cada cual mojara su bocado y pudiera comerlo jugoso. En pequeños lebrillos había pastelillos cubiertos en su superficie (?) de salpicadas especias. Tordos ya asados, acompañados de panes de leche, se precipitaban volando hasta las gargantas; un tumulto de guerra se oía al abrirse paso a empujones los pasteles entre las mandíbulas. Los esclavos solían jugar a las tabas ${ }^{43}$ con trozos de matriz de cerdo y bocaditos de carne. Y los hombres eran entonces grasos y tenían una gran estatura de gigantes ${ }^{44 ”}$.

El fragmento combina diversos elementos de la tradición utópica que ya hemos visto en Hesíodo ${ }^{45}$. La representación de un mundo automático, cuya abundancia gastronómica se describe en detalle, se combina con la idea, relativamente nueva en su formulación, de una paz eterna ${ }^{46}$. Atengámonos, por el momento, a la noción de automatismo. Lo primero que comprobamos en el pasaje es que la sociedad arcaica, de tipo rural, a la que, en el fondo, hacía referencia la Edad de Crono de Hesíodo ya no es el centro de interés de los cómicos y, en consecuencia, la Zeíowpos

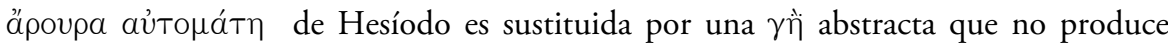
sólo frutos, sino que también asegura la ausencia de enfermedades y peligros, al igual que en la Edad de Crono de Hesíodo. No obstante la formulación es mucho más analítica que en Hesíodo y el espectador ático quizás percibía en ella el eco de recientes penalidades como terremotos o epidemias ${ }^{47}$. Aún así la comedia, como sabemos desde un famoso estudio de Fraenkel ${ }^{48}$, supo utilizar muy bien todas las asociaciones ligadas a la aparición de la palabra clave "automático" ${ }^{49}$, a la cual "si ricollegano tutti i motivi del paese di Cuccagna" 50 .

${ }^{43}$ El tema de los esclavos jugando un humilde juego con apreciados alimentos había ya sido antes

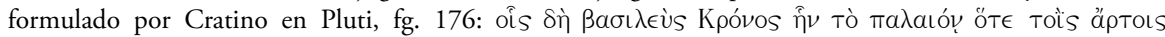

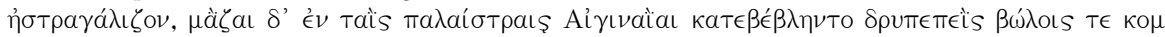
$\hat{\omega} \sigma a \iota$. "en la antigüedad fue su rey Krono, cuando jugaban a las tabas con panes de trigo y en las palestras colgaban hogazas de Egina maduras y llenas de tropiezos como terrones”. Vide comentario en Pellegrino, pp. 45 ss.

45 Otros fragmentos de tenor muy semejante, incluso con sorprendentes correspondencias verbales podemos leer en Los Mineros y Persas de Ferécrates (fg. 113); los Turiopersas de Metágenes o en los Plutos de Cratino (fg. 172). En Aristófanes el motivo aparece ocasionalmente en Acarnienses 976; Avispas 936-9; Asambleistas 730-45; Pluto 476. También lo encontramos en Eúpolis fg. 299; Teopompo cómico fg. 33; Dífilo fg. 14.

${ }^{46}$ Vide mi trabajo "El momento irenístico en la comedia griega antigua", Actas del XII Congreso de la Sociedad española de estudios clásicos, Valencia 22-26 de Octubre de 2007 (en prensa).

${ }^{47}$ Así Pellegrino, pp. 75-77.

${ }^{48}$ Plautinisches im Plautus, Berlin, 1922.

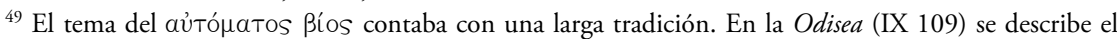
país de los Cíclopes como una tierra donde los frutos crecen a[sparta kai; ajnhvrota, es decir sin necesidad de siembra ni de arado. Prodigiosamente feraz es el maravilloso jardín de Alcínoo (Odisea, VII 112-32) o la lejana isla de Siria descrita en (Odisea, XV 403-14). Ya hemos hecho referncia a las prodigiosas puertas del Olimpo o a los trípodes de Hefesto. En Hesíodo, además de la humanidad en tiempos de Crono, gozaban de las comodidades del aủtó $\mu a t o s$ Bíos los héroes de las Islas de los Bienaventurados (Trabajos 166-73). En el Prometeo liberado de Esquilo (fg. 196, 3-5 Radt) se nos presenta el prodigioso país de los gabios en el que la tierra se siembra a sí misma (aujtovsporoi). Igualmente en Heródoto (III 18) la tierra de los etíopes producía espontáneamente la carne para la fabulosa mesa del sol. E incluso Platón (Político 271 e -272b) se hace eco del aủró $\mu a t o s$ ßíos de la Edad de Crono.

${ }^{50}$ Pellegrino, p. 25. 
Pero, desde el punto de vista cómico, el pasaje es un ejemplo magnífico de cómo la comedia trataba la tradición cómica, llevándola a sus últimas consecuencias lógicas. Si el ßíos es automático, todo debe serlo, no sólo la producción de alimentos, sino la preparación de los mismos o los productos no terrestres, como las aves y los peces. Un automatismo total, que resulta en una burla directa de la tradición utópica.

La lógica cómica llevó la tradición utópica a sus últimas consecuencias. No sólo los alimentos naturales, sino que los mismos objetos han de convertirse en animados para servir al hombre. Así en el fg. 16 de las Bestias de Crates, la substitución del tradicional

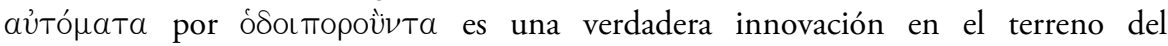
automatismo: la idea de unos objetos "semovientes" resolvía el espinoso problema de la esclavitud, a la que, como es sabido, incluso Aristóteles trató de fundamentar

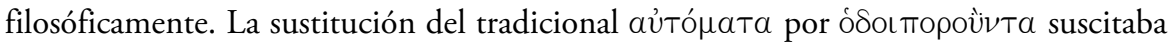

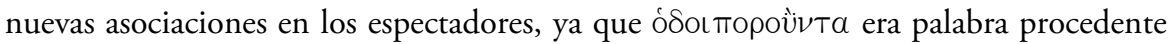
del prestigioso dialecto jónico ${ }^{51}$, de forma que "semovientes" aportaba la idea de objetos evolucionados, sofisticados, técnicamente novedosos y posibles. El fragmento imaginaba también una suerte de bañeras automáticas capaces de llenarse de agua directamente venida del mar. Una talasoterapia avant la lettre. E indirectamente la lógica del automatismo cómico lograba suprimir la esclavitud.

Utopía gastronómica sustentada en el viejo tema del autómatos bios la reencontramos en los Salvajes de Crates $^{52}$ o en los Persas de Ferécrates ${ }^{53}$ y los Turiopersas de Metágenes ${ }^{54}$. Comedias que se hacen eco de cuestiones debatidas en el siglo $\mathrm{V}$, en el marco de análisis permitidos por el descubrimiento y desarrollo de la oposición vó oş$_{\phi} \sigma \mathrm{\sigma ls}$. Aunque apenas tenemos noticias sobre la incipiente etnografía griega, fue sobre esos datos etnográficos sobre los que se basaron los ilustrados griegos en su empeño de construir una teoría del origen y evolución de la humanidad. No estamos bien informados de estas teorías antropológicas, pero tenemos algunos

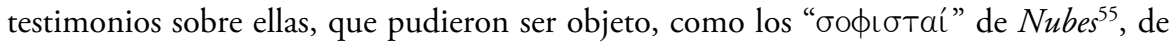
burla por parte de los cómicos griegos.

La elaboración de una teoría de la evolución humana que explicaba el desarrollo desde un estadio de salvajismo, próximo a la vida animal, a la civilización política, no fue entre los griegos pura especulación filosófica o antropológica, lo cual no dejaría, sin duda, de tener cierto interés. La construcción teórica de esa evolución, apoyada, en sus mejores expresiones, en observaciones o noticias etnográficas, dependientes de las tradiciones griegas, fue, antes que nada, un argumento en defensa de la cultura política, de sus instituciones, de sus costumbres y códigos sociales, de las ventajas que todo ello aportaba a las formas de vida griegas ${ }^{56}$. Reconocidas pues la importancia y

\footnotetext{
${ }^{51}$ Vid. Liddell\&Scott, A Greek-Englis Lexicon, s.v. oJdoiporevw.

${ }^{52}$ Fg. 16 K\&A Los Salvajes ( [Agrioi) de Ferécrates, ¿eco de doctrinas sofísticas ${ }^{52}$ ?

${ }^{53}$ Fg. 137 K\&A.

${ }^{54}$ Fg. 6 K\&A.

${ }^{55}$ La búsqueda de ecos sofísticos en la comedia griega, especialmente en los fragmentos de la misma es aún una tarea que completar. Para un estado de la cuestión, limitada, sin embargo a las alusiones a sofistas concretos, vide Christopher Carey, "Old Comedy and the sophists", en The Rivals of Aristophanes. Studies in Athenian Old Comedy, David Harley and John Wilkins eds. Londres, 2000, pp. 419-438.

56 Vide para Protágoras, Gil, L., 1999: "El mito del Protágoras platónico y los fundamentos de la democracia”, en Corona spicea: in memoriam Cristóbal Rodríguez Alonso.
} 
utilidad de tales especulaciones, la comedia se hizo eco de ellas, divulgándolas, degradándolas, a veces, pero aduciéndolas casi siempre en apoyo de la polis democrática en cuyo marco se producía el espectáculo cómico.

$\mathrm{Y}$ es muy significativo que la comedia comenzara a interesarse por esas especulaciones sofísticas y filosóficas, cuando empezó a tomarse conciencia de que, a pesar de todos sus defectos, la polis era por entonces el mejor de los mundos posibles. Y por ello comenzamos a encontrar comedias donde ciudadanos atenienses abandonan la ciudad en busca de mundos ideales y perfectos.

Pues bien, entre las comedias, donde el protagonista huido de la ciudad buscaba la superación de su estrecha condición de ciudadano ateniense, se encuentra los Salvajes de Ferécrates ${ }^{57}$.

Precisamente esta comedia de Ferécrates debió de aportar alguna novedad, toda vez que Platón en el Protágoras (327c-e) hace mención de la misma.

"Ten ahora también por seguro igualmente que el ser humano que te parezca ser el más injusto de cuantos han sido criados entre hombres y leyes, es justo y promueve la justicia, con tal de que lo juzguemos en comparación con quienes no han recibido ninguna educación $(\pi \alpha \iota \delta \in(i)$ ni conocen tribunales ni leyes ni ningún principio que los fuerce absolutamente a cuidarse de la virtud. Tales individuos serían, por el contrario, uno salvajes del tipo de los que el ańo pasado representó el comediógrafo Ferécrates en las Leneas. No cabe duda de que, si te encontraras entre tales tipos, te regocijarías de toparte con Euribato y Frinondas y te lamentarías ańorando la perversidad de los ciudadanos de aquí"

De este texto se desprende que los valores de la civilidad, de la traı́fía, de los valores ciudadanos, contrapuestos a la anomía y misantropía de los Salvajes, constituían la idea dominante de la comedia, inspirada en el famoso mito del Protágoras.

Es muy posible que también la comedia basara su comicidad en la perversión de los diversos códigos atenienses: alimenticios, religiosos, funerarios, familiares, sociales, sexuales, lingüísticos, etc. ${ }^{58}$ Los griegos habían elaborado ya construcciones teóricas con las que examinar las características del $\mathrm{Otro}^{59}$. La etnografía, la tragedia y quizás también las especulaciones sobre la evolución humana y el relativismo ético, tal como aparece expresado en los dissoi logoi, por ejemplo, proporcionaban material suficiente para el tratamiento cómico del tema.

Algunos fgs. de la comedia permiten insertarse en una reconstrucción tal. Así el frag. 7 (Ateneo, IV 171c) parece remitir, con la mención, de los $\pi \rho 0 \tau \in \nu \theta \omega ̈ \nu$ a una institución ateniense, la fiesta de las Apaturias, de las fratrías de las tribus jonico-áticas.

\footnotetext{
${ }^{57}$ Un comentario a los fragmentos conservados puede leerse en Marcella Farioli, op. cit., pp. 174 ss. y Paola Ceccarelli "Life among the savages and escape from the city in Old Comedy" en The Rivals of Aristophanes. Studies in Athenian Old Comedy, David Harley and John Wilkins eds. Londres, 2000, pp. 453-472.

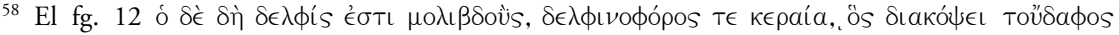

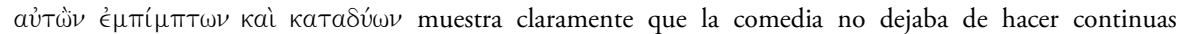
referencias a hechos, objetos o situaciones bien conocidos de los espectadores, en este caso un artefacto defensivo de las naves. El fragmento no permite una interpretación más exacta.

${ }^{59}$ M. DORATI, Le Storie di Erodoto. etnografia e racconto, Oxford: Clarendon Press, 2000; Para la tragedia, E Hall, Inventing the barbarian Greek Self-Definition through Tragedy, OXFORD, 1991; para la comedia T. Long, Barbarians in Greek Comedy, Southern Illinois University Press, 1986.
} 
Más exactamente los $\pi \rho 0 т \epsilon \nu \theta a i ́$ eran los que probaban la comida que se celebraba en el primer día de las Apaturias, llamado, por eso, $\Delta$ орті́ $\alpha^{60}$.

El fg. 13, "y las bellotas y las piñas y las peras salvajes que han sobrado" parece hacer referencia a la pobre alimentación de los salvajes, constituida por hierbas y frutos salvajes no cultivados ni cocinados. Las bellotas especialmente eran alimento de $\operatorname{cerdos}^{61}$; el hombre se alimenta de ellas sólo en una fase primitiva anterior a la agricultura $^{62}$. Todo ello sugiere una oposición entre la pobre e incivilizada alimentación de los salvajes en oposición a la sofisticación de la cocina ateniense. Conviene, sin embargo, no olvidar que un rasgo de la mitología áurea, del

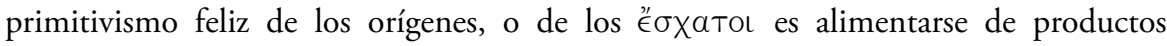

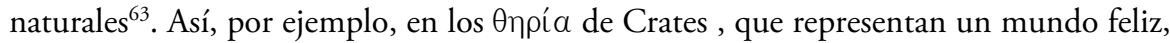
tanto en el fg. 18

"Llevando una vida feliz,

Y abundancia de alimentos".

Como en el 19, podemos ver quizás no sólo la oposición entre el vegetarianismo de los salvajes y la cocina ateniense, sino una probable alusión al vegetarianismo de los orígenes, cuando hombres y animales vivían en fraternidad y armonía ${ }^{64}$.

No obstante, algún otro fg. parece denotar la ferocidad de los salvajes, desconocedores de toda técnica culinaria. No olvidemos que la omofagia era percibida por los griegos como una forma próxima al canibalismo ${ }^{65}$. Así en el frag. 14 (Ateneo VII 316 e) se ha querido ver una referencia a las tendencias antropofágicas del coro

"Vivir de tagarninas ${ }^{66}$, de brócoli,

De olivas salvajes. Y, cuando ya no puedan más de hambre,

Remorderse por la noche los dedos, como hacen los pulpos ${ }^{67 "}$.

No sé si hay realmente en este fragmento una referencia al posible canibalismo de los salvajes. Desde luego, no se deduce del texto ${ }^{68}$. Más bien, parece indicar la extrema

\footnotetext{
${ }^{60}$ Liddell\&Scott s.v. Dorpiva, que recogen el testimonio de Phillyl. 8.2. que glosa la palabra como

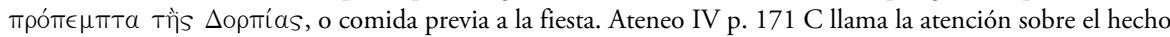

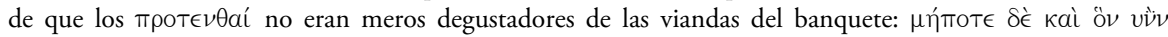

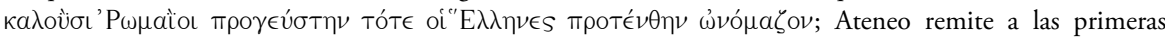
Nubes de Aristófanes, (Nubes 1196-1200). Dover (Aristophanes Clouds, Oxford, 1970) comenta la palabra como "officials...responsible for seeing that the food prepared for the festival Apaturia was satisfactory".

${ }^{61}$ Homero, Odis. X 241-243 y XIII 407-410.

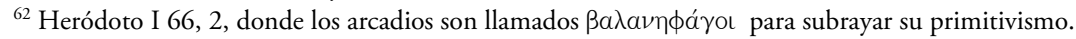

${ }^{63} \mathrm{La}$ idea de que en un estadio originario de inocencia y felicidad los hombres no comían carne la encontramos en numerosas fuentes antiguas, por ejemplo Schol. Odys. III 441; Schol. Ad Hes. Gaisford p. 116, 9; Platón Resp. 372 d. Vide Hausleiter, Der Vegetarismus in der Antike, Berlin, 1935, pp. 54 ss.

${ }^{64}$ Vide Johannes Haussleiter, Der vegetarismus in der Antike, Berlin, 1935 pp. 54 ss.

${ }^{65}$ Vide Marcella Farioli, op. cit. pág. 177 y nota 108

${ }^{66}$ Traduzco algo arbitrariamente el término $€ \nu \nu \rho \nu \sigma \kappa \circ \nu$ o ă $\nu \rho \rho v \sigma \kappa o \nu$, identificado con la scandix australis, planta salvaje mediterranea. Vid. a propósito Georg Rehrenböck, Pherekrates-Studien, Dissertatio, Viena, 1985, p. 237.

${ }^{67}$ Cf. Hesíodo, Erga 524-6.
} 
pobreza de la alimentación de los Salvajes. Quizás el fg. 5 (Poll. X 150) parece aparentemente sugerir prácticas antropófagas:

"No dudes que te considerarás bendito, cuando

Esos te entierren. B- De eso nada, serán ellos los que me llamarán bendito, Aunque dónde voy a encontrar tantas jarras fúnebres ${ }^{69}$ "

¿Debemos entender el pasaje en el sentido de "Te considerarás feliz si te entierran,

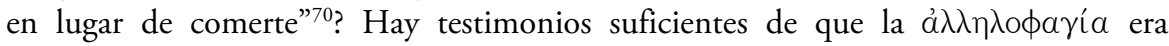
considerada marca de sociedades bárbaras y marginales.

Pero no es la única explicación posible. Despreocuparse de los cadáveres es ya de por sí suficiente signo de barbarie, algo más propio de animales que entre los humanos $^{71}$. El fg. 10 (Athen. VI 263b) plantea problemas de otra naturaleza

"Ya que entonces nadie tenía un esclavo, ni un Manes ni una Sekis,

Sino que las mujeres debían hacer todo el trabajo de casa.

Y además molían el trigo de buena mañana,

$\mathrm{Al}$ punto que la aldea resonaba con el estrépito de las muelas"

Se ha pensado que el pasaje, con su referencia a la ausencia de esclavos podría ponerse en relación con la Atenas idealizada de antaño ${ }^{72}$, opuesta a la decadencia de la ciudad actual y a los salvajes de otro lado ${ }^{73}$.

Todo ello es sumamente oscuro y sujeto a hipótesis de todo tipo. Pero no cabe duda de que en esa comedia se contraponían las costumbres políticas atenienses a supuestas prácticas salvajes o primitivas.

Constatamos, por otro lado, que del salvaje existieron en la cultura griega dos visiones: una progresista, donde el salvaje era representante de la animalidad originaria, tal como, por ejemplo, parece recoger los"A $\gamma \rho \iota \mathrm{ou}$ de Ferécrates. Y otra pesimista, donde el Salvaje es representante de la felicidad de los orígenes, y detentador de las más excelsas virtudes morales y cívicas como la concordia, la hospitalidad, la frugalidad.

${ }^{68}$ Tal parece ser también la opinión de Paola Ceccarelli, op. cit. p. 457. Marcella Farioli, op. cit. p. 78 no excluye del todo una posible alusión al canibalismo de los salvajes.

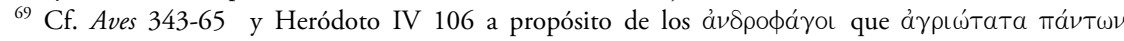

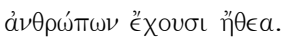

${ }^{70}$ Así Paola Cecarelli, op. cit. p. 456 y Marcella Farioli, op. cit., p. 178-9.

${ }^{71} \mathrm{Cf}$. Los masagetas e isedones se comen a sus difuntos. Cf. Heródoto I 216, 2-3; IV 26.

${ }^{72}$ Una situación diferente, claramente utópica, representa el fg. 16 de las Oүpía de Crates, donde la ausencia de esclavos es posible gracias a la existencia de un mundo automático. Vide mi trabajo "La lengua de la Utopía”, en Registros Lingüisticos en las lenguas clásicas, Universidad de Salamanca, 2004, pp. 149-172.

${ }^{73}$ Cf. Heródoto VI 137,3 quien recoge la tradición de que en la época remota de enemistad con los Pelasgos, eran las mujeres las encargadas del trabajo domestico, ya que no había esclavos ni en Atenas ni en ninguna parte de Grecia. Cf. La misoginia cómica de los Plutos y los Quirones de Cratino, cuando en Atenas las mujeres trabajaban y los hombres permanecían ociosos en casa. Y cf. Asambleístas 651-54 donde las reformas de Praxágoras no afectan a las mujeres ni a los esclavos. Quizás no haya que descartar una broma erótica, si tal es la connotación de un canto popular Carmina Populari, Page, P.M.G." A $\lambda \in \mathrm{l}, \mu u ́ \lambda a$,

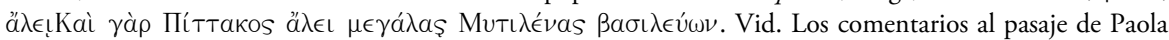
Ceccarelli, op. cit. p. 458 y Marcella Farioli, p. 180 s. 
Ambas visiones están presentes en los pueblos de los extremos: unos son felices, como los etíopes; otros, son bárbaros, como los andrófagos.

Ninguno de los fragmentos por sí solo prueba que la comedia tuviera como tema las teorías sofísticas sobre la evolución humana. Todos ellos en conjunto, sin embargo, junto al testimonio de Platón, inducen a pensar que la comedia, en la modalidad cómica de "escape de la ciudad", trataba el tema de la superioridad del ordenamiento legítimo de la ciudad sobre las visiones más o menos utópicas de mundos felices y/o salvajes como los que describían bien las propias tradiciones folclóricas griegas o bien los relatos de la incipiente etnografía de la época.

Otra variante cómica es la representación de una naturaleza excepcionalmente benéfica como en las Sirenas de Nicofonte ${ }^{74}$; como creación de ciudades ideales, que resultan finalmente ser distopías, muy alejadas del país de Jauja de otras comedias, tanto si se sitúa en el cielo, como en Aves, o en los infiernos como en los Mineros ${ }^{75}$ de Ferécrates $^{76}$. La comedia utiliza todas las tradiciones utópicas, las combina, las reubica, las actualiza en pueblos históricos bien conocidos como los lidios, los frigios, los persas ${ }^{77}$, las adapta a sus propósitos dramáticos y crea una nueva realidad en la que se examinan, siquiera sea al modo cómico, cuestiones candentes como la de ciudadanía, la esclavitud $^{78}$, la vida en estado natural, etc ${ }^{79}$.

$\mathrm{Y}$ todo ello naturalmente desde la perspectiva ateniense del siglo $\mathrm{V}^{80}$. Es cierto que en algunas de estas utopías, como las Asambleistas de Aristófanes, influyeron también las ideas reformistas de los primeros utopistas griegos, de Faleas, de Hipodamo y puede que del mismo Platón ${ }^{81}$.

$\mathrm{Y}$ es igualmente posible que la propia comedia ática llegara a ser consciente de sus propios excesos utópicos y convirtiera el tema en un lugar común del que sólo cabía

\footnotetext{
${ }^{74}$ Fg. 21 K\&A.

${ }^{75}$ Fg. 113 K\&A. Vide mi trabajo, "El infierno en escena: representaciones del más allá en la comedia griega" en Idee e Forme nel teatro greco, Atti del Convegno italo-spagnolo (Napoli, 14-16 ottobre 1999). A. Garzia ed., Nápoles, 2000, pp. 359-81.

${ }^{76}$ Para un comentario a estos temas cómicos vid., sobre todo, MATTEO PELLEGRINO, Utopie gastronomiche nei frammenti dell' archaia, Eikasmos, Studi 4, Bolonia, 2000. Vide también los excelentes comentarios de M. Farioli, Mundus Alter, passim. Útil aún es la antología comentada de JEAN CLAUDE CARRIERE, Le Carnaval et la politique. Une introduction à la comédie grecque suivie d'un choix de fragments, Paris, 1979.

${ }^{77}$ Vide el excelente estudio de Ma. De Fátima Sousa e Silva, "O estrangeiro na comédia de Aristófanes” en Ensaios sobre Aristófanes, Lisboa, 2007 pp. 275-297, quien lleva a cabo un interesante análisis de los procedimientos fundamentalmente lingüísticos para la explotación cómica del famoso lujo persa.

${ }^{78}$ No es exactamente cierto que la discusión sobre la esclavitud esté ausente de la comedia. En algún fragmento se hace mención explícita de ella. Y puede decirse que la comedia ática es el único género literario antiguo donde, siquiera fuese al modo cómico, se trató dicha cuestión. Para un poosible influjo de los sofistas en estas representaciones cómicas de la utopía vide mi trabajo-"Los salvajes de Ferécrates, ¿eco de doctrinas sofísticas? En Actas del I Congreso Internacional de Teatro Clásico griego. Teatro y sociedad: las relaciones de poder en época de crisis, Valencia, 12-13 de Marzo de 2007.

79 Para un excelente análisis de las tradiciones utópicas en Aristófanes vide BERNHARD ZIMMERMANN, "Nephelokokkygia. Riflessioni sull' utopia comica” en Carnevale e Utopia nella Grecia antica, WOLFANG RÖSLER\& BERNHARD ZIMMERMANN eds., Bari, 1991, pp. 55-127.

${ }^{80}$ Vid. PAOLA CECCARELLI, "Le monde sauvage et la cité" Etudes de Lettres, 1992, pp. 23-37

${ }^{81}$ Para Faleas e Hipodamo, vid. LAWRENCE GIANGRANDE, "Les utopies grecques" Rev. Et. Anc. LXXVIII-LXXIX, 1976-77, pp. 120-128; L. BERTELLI, L’utopia greca. pp. 529 ss.
} 
burlarse. Así me ha parecido detectarlo en algún pasaje de los Persas de Ferécrates ${ }^{82}$ y quizás haya que revisar algunas de las conclusiones que, siempre de un modo tentativo, hemos alcanzado.

82 “Ferécrates, Persas (fg. 137) Studia Philologica Valentina, 9 (2206) ISSN 1135-9560 pp. 131-145 


\section{Série}

\section{Documentos}

Imprensa da Universidade de Coimbra

Coimbra University Press

2009

- $\mathrm{U}$

C • 